\title{
Applying the principles for livable communities
}

\author{
Bangsuk Jantawan ${ }^{1,2}$, Phongphanich Nara ${ }^{1, *}$, Cheng-Fa Tsai ${ }^{2}$ \\ ${ }^{1}$ Dept. of Tropical Agriculture and International Cooperation, National Pingtung University of Science and Technology, Pingtung, Taiwan \\ ${ }^{2}$ Dept. of Management Information Systems, National Pingtung University of Science and Technology, Pingtung, Taiwan
}

\section{Email address:}

jantawan4@hotmail.co.th (B. Jantawan),rara_ha@hotmail.com (P. Nara), cftsai2000@yahoo.com.tw (Cheng-Fa T.)

\section{To cite this article:}

Bangsuk Jantawan, Phongphanich Nara, Cheng-Fa Tsai. Applying the Principles for Livable Communities. American Journal of Environmental Protection. Vol. 3, No. 4, 2014, pp. 179-184. doi: 10.11648/j.ajep.20140304.12

\begin{abstract}
The Baan Haad Rin (BHR) is a coastal community at the Koh Phangan Island in the Suratthani Province, and is located in a peninsular beach area on the southern tip of this island. There are two beautiful beaches, Haad Rin Nai Beach (Sunset Beach) in the west and the Haad Rin Nok Beach (Sunrise Beach) in the east. The BHR is the main place in tourism destination choice due to the famous Full Moon Party which takes place on the Sunrise Beach each month. The beautiful beach and famous party have increased many visitors since the 1980s. The BHR has grown to accommodate the new visitors and the tourism development. The environmental characteristics of the BHR have rapidly changed due to the impacts of tourism developments and natural disasters. These environmental impacts have halted the growth of tourism industry and community development. Therefore, this study focuses on the application of the principles for livable communities (PLC) to propose the guidelines for solving the environmental impacts of the BHR. The result of study also presents the summary of concept and action plans for environmental management and sustainable development.
\end{abstract}

Keywords: Environmental Management, Principles for Livable Communities, Sustainable Development

\section{Introduction}

According to the Department of Tourism (DOT) and the Tourism Authority of Thailand (TAT), they report that the coastal tourism destination is one of the fastest growing tourist markets within the Thailand's tourism industry. The tourism industry in the Southern Thailand is the largest tourism revenue of country, which makes revenue of $5,819.54$ million US dollars in 2011 [1, 2]. Moreover, most coastal tourism destinations are located in the Southern Thailand. The Koh Phangan Island consisting of many beautiful landscapes and coastal recreation areas is located in the Suratthani Province, Southern Thailand [2, 3]. This island covers an area of 194 square kilometers with over $70 \%$ as mountains and tropical forest [3]. The surrounding ocean contains numerous coral reefs and fishes with an exuberance of marine life [3]. As the Thailand's fifth largest island and one of the most popular coastal tourism destinations, it is one of the main revenue of the Thailand's tourism industry $[2,3]$.

Furthermore, DOT and TAT also mention that the Koh Phangan has often been voted as one of the top destinations. For example, this island is voted as the fifth and forth of the Top Ten Beach \& Sun Destinations in Asia from the Trip
Advisor Traveler's Choice 2010 and 2012 Awards [2], respectively. In most of this island, high season starts from January to March every year [1,2]. This island has a famous party held monthly on the Sunrise Beach of the BHR, namely the Full Moon Party [3]. It is considered as the biggest party on the beach in Thailand. It attracts approximately $15,000-30,000$ tourists from many countries around the world to the BHR $[1,2]$.

However, the BHR has faced significant impacts on environmental protection and management. The impacts to its environment are mostly caused by the effects of intensive tourist activities and natural forces [3, 4]. In order to reduce the impacts, the management of BHR is taking the apparent conflict between community development and environmental protection into account. There are many environmental impacts under the causes of tourism development and natural disaster. For example, the visual pollution and deforestation on the Haad Rin Hill are destroyed by the constructions of hotels and resorts. The coastal erosion on the Sunset Beach is also caused by the storm surges during monsoon season into the coastal areas $[3,4]$.

This study focused on the PLC to apply the concept of ten principles for solving the environmental impacts of the BHR. The concept of PLC was created by the American Institute of 
Architects (AIA) to achieve a better and more livable built environment. It also has been applied in the quality of life to improve community's quality of life through design $[5,6]$. In addition, the PLC has been required new ways of thinking about the interrelationship between economy, environment and community aspects. It focused on the sustainable development to make the sustainable livable communities [7].

The purposes of this study are to explore the impacts of environment, to review and apply the PLC for designing a concept plan, and proposing the guidelines for the action plans of environmental management and sustainable development of the BHR.

\section{Literature Review}

\subsection{Principles for Livable Communities}

In 1960, the concept of the urban design was to understand the relation between environmental images and urban life. It was the process of design guidelines for physical development of cities, preservation, and improvement or shift to approaching the quality of life [8]. There was applied the urban design concept to explore the most noticeable effect of external factors affecting any environment. It was also brought up an analysis of urban landscape and environment or site analysis to provide empirical research on city planning [7]. The site analysis is to provide a full understanding of those environmental characteristics. It will have implications for the development of the concept plan that can contribute to good urban design $[7,8]$.

Subsequently, the PLC was developed by the AIA to achieve a better built environment of urban. It focused on the environment making, which involves the design of urban spaces and landscape areas to encourage the sustainable livable communities [5]. There are ten major principles including: design on a human scale, provide choices, encourage mixed-use development, preserve urban centers, vary transportation options, build vibrant public spaces, create a neighborhood identity, protect environmental resources, conserve landscapes, and design matters [5]. The PLC has been applied on urban environment improvement to promote the urban and/or community's quality of life through ten major principles. It facilitated in accessibility and accommodates a diversity of activities, and it proposed the preservation of historic structures to promote sense of place $[5,6]$. In term of sustainable development, the PLC has been focused on the future to sustain human society within the contexts of the natural environment and urban landscape. It also provided form and definition to design the urban concept plan for sustainable development of environment, society, culture, policy, and aesthetics [6, 7].

\subsection{Sustainable Development}

The concept of sustainable development continued from the environmentalism and grew to prominence in the $1970 \mathrm{~s}$
[9]. According to the report of The World Commission on Environment and Development (WCED), it defined sustainable development as "the development that meets the needs of the present without compromising the ability of future generations to meet their own needs" [10]. The United Nations Environment Programme (UNEP) also referred the aims of sustainable development including economic, social, and environmental aspects [11].

In tourism, the World Tourism Organization (WTO) proposed a meaning of sustainable tourism development (STD) as "the management of all resources in such a way that economic, social and aesthetic needs can be fulfilled while maintaining cultural integrity, essential ecological processes, biological diversity and life support systems" [12]. In addition, the UNEP referred that many researchers studied on sustainable development of the coastal tourism destinations, which the results of their research showed that the impacts of coastal resources were mostly caused by the impacts of tourism [11]. In order to minimize the coastal resources impacts, the WTO and the UNEP proposed the tourism development plan based on the concept of STD, which it focused on the appropriate planning of tourism growth with regard to the capacity of community $[12,11]$.

\section{Material and Methods}

This study collected the secondary data on the PLC and sustainable development from the Thai government's publications, research papers, and literatures involved. In field survey, the primary data were collected from the interviews on the environmental impacts with local administrative agencies of the BHR during the October and November 2013. It also used the camera and maps for observing the environmental characteristics.

\subsection{Study Area}

Koh Phangan is one of the most visited islands in the Thailand because of its diversely beautiful landscapes and complete ecosystems. In the history of the island has been a long time favorite destination of the Thai Royalty specifically the King Rama V, who lived from 1868 until 1910. He visited the island at least fourteen times between the years of 1888 to 1909 due to the beautiful and breathtaking tourist attractions throughout the island [3]. Presently, many coastal tourism destinations became popular with tourists escaping the tourist inflow to the island since the 1980s [2].

The BHR is one of the most visited places in this island because of its delightful beaches and great Full Moon Party. This place can be divided into two sections including the Sunrise Beach and the Sunset Beach. The Sunrise Beach where many beach clubs and bars are available is one of the biggest beaches on the island, and it has various beach activities at daytime and the famous party at night. The Full Moon Party was originally founded in 1988 that a local people, arranged a party and danced on the beach at night for travelers and small group of friend from the Europe [3]. It 
gains fame through word of mouth as legend of party among backpacker tourists, and become part of the itinerary of many tourists for visiting at the BHR $[3,2]$. The Sunset Beach is one of the best water activities on the island such as diving and snorkeling, and fishing [2]. The urban areas have many public facilities and tourism services to serve the requirements of visitor and resident $[3,4]$.
Therefore, the study area covers the Sunrise Beach, the Sunset Beach, and the urban areas of the BHR. It is located in the Baan Tai Municipality of the Koh Phangan Island. The boundary of the study area has been drawn around a center of the BHR (Red line) with use a scaled map within a 400-metre radius (Figure 1).

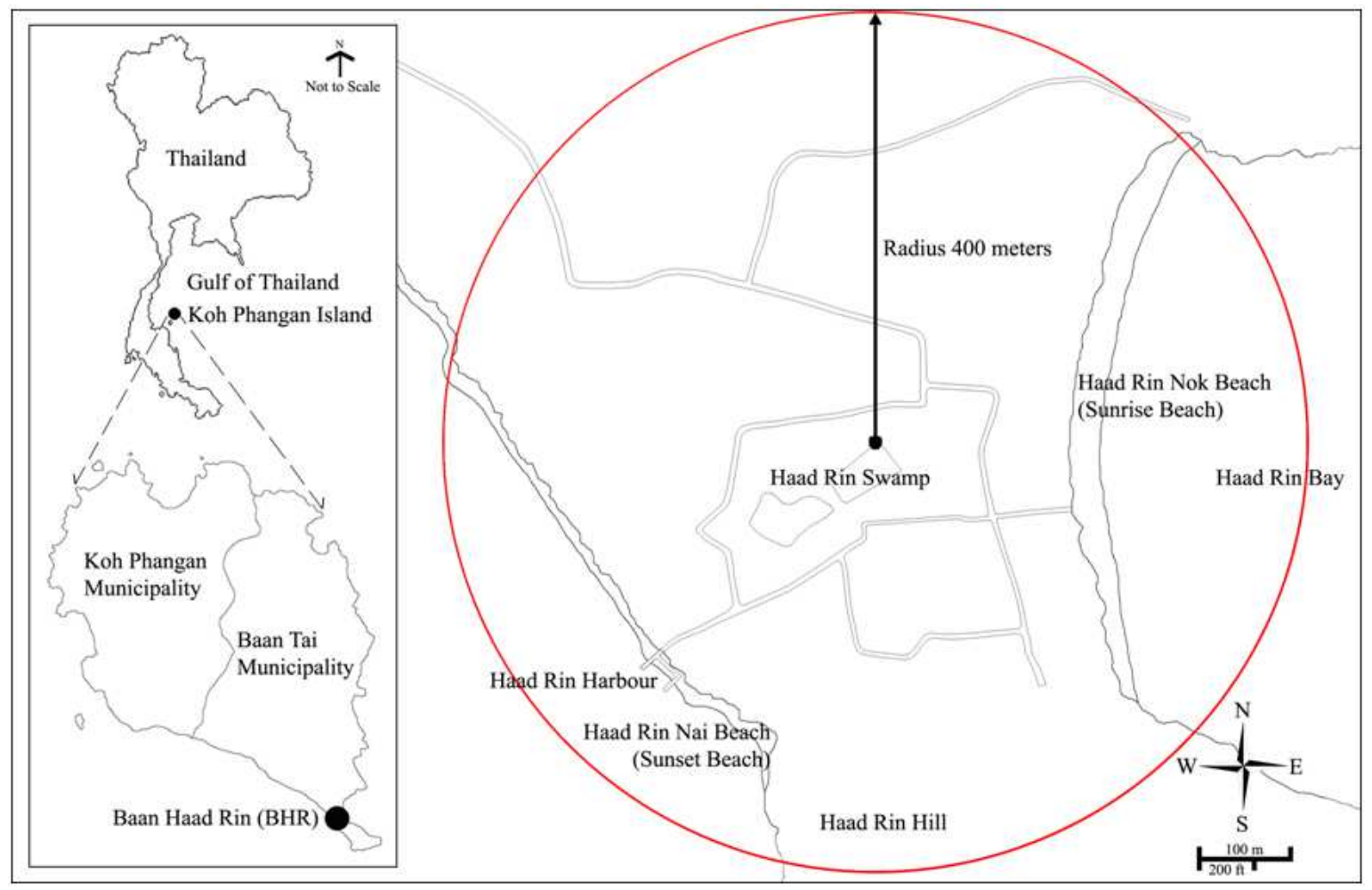

Figure 1. Location of the BHR.

\section{Results and Discussions}

\subsection{Environmental Impacts}

The results of primary data indicate that environmental characteristic of the BHR have clearly changed under the combination of natural and anthropogenic forces. It shows that most of local administrative officers mention a significance of the five key issues, which can be divided into thirteen environmental impacts in Table 1.

Also, the findings of study show that the most of respondents have very serious on the pollution issues including five major kinds of pollution. Three signal specific populations as wastewater, solid waste, and visual pollutants, have broadly affected on the environment and tourism of the BHR. The local administrative agencies of the BHR mention that the ecosystem and natural resource are destroyed by the construction of buildings and tourist activities. Table 1 shows the three main types of ecosystem and natural resource impacts which comprise coastal erosion, destruction of habitats, and loss of biodiversity. Furthermore, the natural disasters also cause extreme weather, such as windstorm, storm surge and coastal flood, which can cause great loss of life and property damage in the study area.

Accordingly, the Town and City Planning Act (TCPA) of the Koh Phangan District for 2007 indicated that the impacts of land use change were caused by property developers who ignored the regulations of city planning. The lowly residential density and agricultural areas under the TCPA were encroached by the construction of hotels and resorts in order to meet tourist demand. The open spaces and beautiful landscapes had also been destroyed by the high-rise buildings and the non-standard construction. The results also show that the weakness of transportation of the BHR is poor sidewalks and roads, and it lacks continuity of transport systems, resulting in continual problems of the transport accidents (Table 1). 
Table 1. Environmental Impacts of BHR.

\begin{tabular}{lll}
\hline Key Issue & Impact \\
\hline \multirow{3}{*}{ Ecosystem and Natural Resource } & 1) & Coastal erosion was caused by storm surge and construction of building. \\
& 2) & Loss of natural habitats was caused by deforestation and infestation of tourist activities. \\
& 3) & Loss of biodiversity was caused by interference and destruction of tourist activities. \\
& 1) & Air pollution was produced by motor vehicles. \\
2) & Noise pollution was produced by motor vehicles and clubs or bars. \\
Pollution & 3) & Wastewater pollution was produced by accommodations, restaurants, and residences. \\
& 4) & Solid waste was pollution produced by tourists and residents (e.g. cans and bottles). \\
Natural Disaster & 5) & Visual pollution was destroyed by buildings and street furniture. \\
Infrastructure and Facility & 1) & Flood and storm surge were caused by monsoon and windstorm. \\
& 1) & Water scarcity was caused by waterworks cannot built large reservoir to produce water supply. \\
Land-use and Transportation & 2) & Loss of access to recreational facilities and services (e.g. recreation areas, restroom facilities for people with \\
& 1) & Cisabilities and older people). \\
& 2) & plange of land use and open space were caused by property developers ignored the regulations of city \\
\end{tabular}

\subsection{Applying the Principles for Livable Communities}

This study proposes the application of the PLC. It also summarizes the concept plan of BHR below.

\subsubsection{Design on a Human Scale}

The physical characteristics of BHR should provide a means for local people and stakeholders to incorporate more-compact building design and pedestrian-friendly communities. In this part, the building control zones are designed by controlling the high rise buildings and congestion of buildings in the commercial area only (Red color). The public open spaces are proposed by reducing the footprint of new constructions and preserving more open spaces for human activities and events, and are accessible to the public (Green space area). Also, these public open spaces are proposed to provide for recreational use and retention of rainwater and flood.

\subsubsection{Provide Choices}

The housing is a major part of the way communities grow, because it becomes an important share of new construction and development. This principle focuses on the variety choices in housing and various public facilities with people in various levels. This plan is proposed by increasing the new stores (Red color), green walkway (Green line), transport systems (Red line and Black line), into the BHR's concept plan. It also encourages lively neighborhoods and accommodates residents of people lives into the residential area (Yellow color).

\subsubsection{Encourage Mixed-Use Development}

The BHR's land should support mixed land uses as a major component of sustainable places to live. The principle of mixed land use can supplement the liveliness of study area by setting new recreational facilities such as stores, tourist information centers, parks, and pedestrian malls into the BHR's concept plan. In this part, the key recreational facilities are designed by putting new stores into the mixed land use areas (Orange color) and setting new tourist information centers into the recreational areas (Coastal protected area), and are proposed by controlling the building form in the study area for limiting visual pollution. Also, this plan is offered by determining new parks, sidewalks and pedestrian-friendly or green walkway (Green line) to connect between mixed land use areas and recreational areas.

\subsubsection{Preserve Urban Centers}

This principle is supported by avoiding new construction and using advantage of existing public buildings. Thus, the BHR should restore the urban centers, and promotes stability for city neighborhoods. This plan proposes to utilize the existing public services and buildings (Neighborhood center), and conserves the open space (Green space area) of urban center. It also offers to revitalize the infrastructure such as sidewalks and pedestrian-friendly or green walkway (Green line), and fills the street furniture for facilitation of users.

\subsubsection{Vary Transportation Options}

The BHR should begin to implement new approaches to transportation planning for giving people a variety of transportation options and getting comfortable. This plan keeps the open spaces to design the walking and biking on the green walkway. It is offered by using the public transit such as mini bus, which it is good coordination between the land use, open spaces, and transport system. Also, this principle is proposed by encouraging transit driver training and creating connectivity within road networks and sidewalk systems (Red line, Black line, and Green line) into the study area.

\subsubsection{Build Vibrant Public Spaces}

The public spaces for encouraging community and stakeholder collaboration are very importance. This principle offered by creating good recreational facilities and services for people with disabilities and older people. This plan proposes the public open space (Green space area) on the urban center of BHR. This area is presented by designing public open spaces such as parks, playground, and outdoor art exhibition or public events for participation of people. It can apply as the relief area to help the victims of various disasters. 


\subsubsection{Create a Neighborhood Identity}

This principle is proposed by encouraging outstanding neighborhoods and creating pride in the community. A neighborhood identity is created by a "sense of place". This plan shows the elements of landscape architecture and identity of BHR such as landmark and fisherman museum into the urban center (Green space area). Also, this plan encourages local people able to identify and utilize opportunities on the public areas to make new development project for environment protection and beauty of community such as the fisherman village.

\subsubsection{Protect Environmental Resources}

The BHR's swamp is very important to the water consumption of local waterworks and local people. This plan proposes the conservation of water resource (Swamp) at the urban center (Green space area). The land area around swamp is destined by the main concept of waterfront design for creating the park and playground and protecting water resource of the BHR.

\subsubsection{Conserve Landscapes}

The BHR should establish coastal landscapes around the study area, because of open space can increase quality of environment and health benefits, and protects plants and animals live. This plan designs the beach setback during 20-50 meters along both beaches for creating coastal recreation area and green belt area. These protected areas are designed to resist windstorm and storm surge will protect beaches and people.

\subsubsection{Design Matters}

This principle is the basis of livable communities. This plan applies the aims of sustainable development to propose the environmental protection and management, which it focuses to the walk able and healthy communities. It provides the process of design guideline for physical development of BHR, and protects environment and ecology systems for approaching the quality of life. It also encourages the elements of urban design including the public space or open spaces, streetscape and transit facilities, and building form. All elements can be formed as landmarks, parks, or street trees (Green space area and green walkway) for supporting all people in the study area.

\section{Conclusion}

The results of this study show that the environment impacts of the BHR are highly considered by respondents. For this reason this study has combined the results between these environment impacts and the PLC together to proposes the concept plan for improving the environment impacts in contexts of the BHR, which it presents that the elements of urban design and detail designs into the study area.

Therefore, the BHR's concept plan has developed to propose the action plans and guidelines for environmental management and sustainable development. In addition, these results of this study may propose useful information and example of tourism development at coastal community, especially for achieving a sustainable livable community.

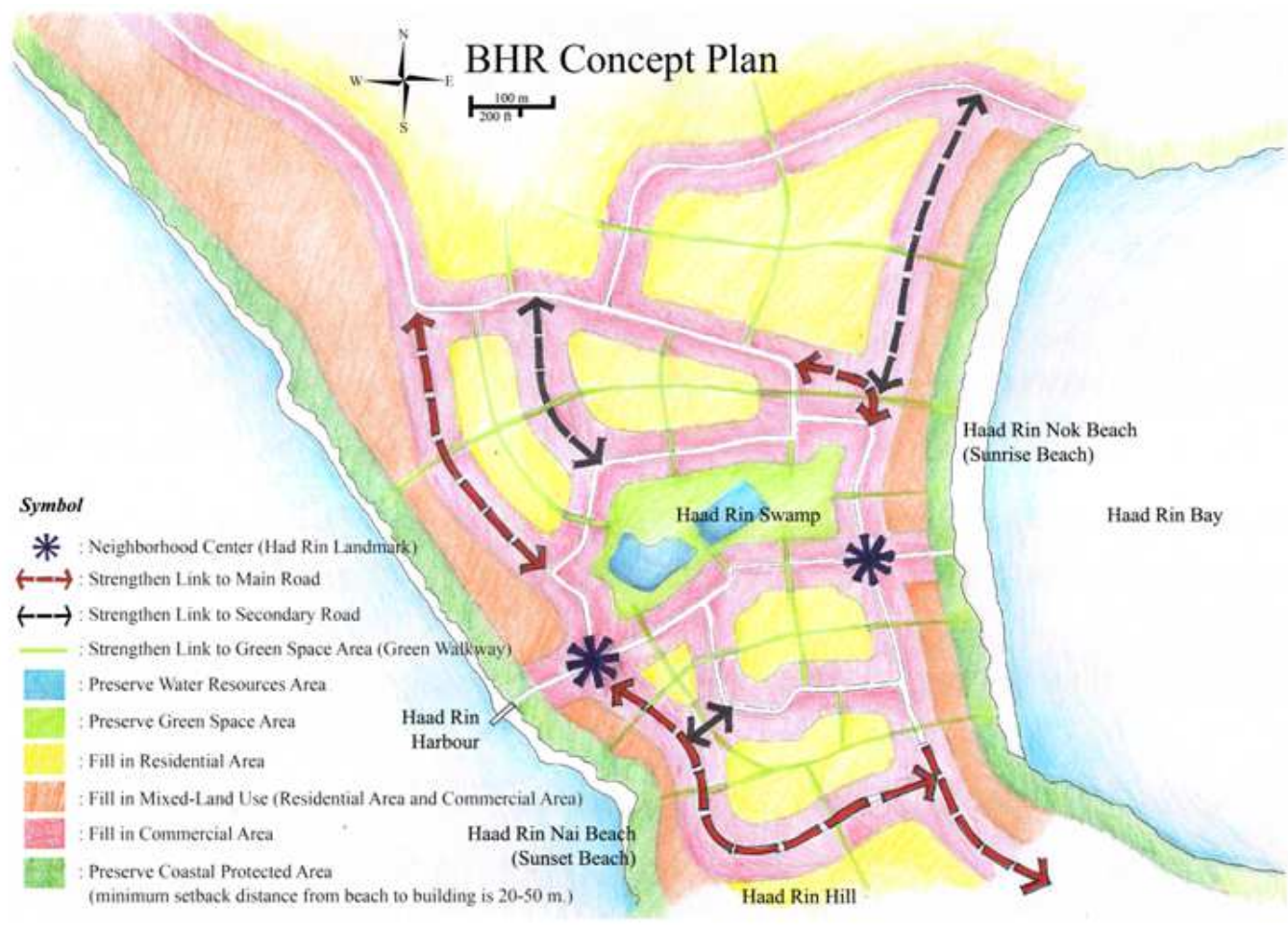

Figure 2. A Concept Plan of the BHR. 


\section{Acknowledgements}

We gratefully acknowledge Department of Tropical Agriculture and International Cooperation and Department of Management Information Systems, National Pingtung University of Science and Technology, Taiwan for providing inspire fellowship to carry out this work. Lastly, we would like to express thank to the local administrative agencies of the BHR for their opinion.

\section{References}

[1] Department of Tourism, 2011, Tourist Arrivals in Thailand, http://www.tourism.go.th/index.php?mod=WebTourism\&file $=$ content\&dID $=6 \& \mathrm{cID}=276$, accessed 12 August 2012 .

[2] Tourism Authority of Thailand, 2012, Tourism Statistics in Thailand, http://www2.tat.or.th/stat/web/static_index.php, accessed 12 August 2012.

[3] Malam, L., 2008, Geographic imaginations: Exploring divergent notions of identity, power, and place meaning on Pha-ngan Island, Southern Thailand. Asia Pacific Viewpoint, vol. 49, pp. 331-343.

[4] Phongphanich, N., Mao, G.G. and Yen, T.B., 2013, Impacts of Tourism Development in Ban Had Rin Community at Koh Phangan Island, Thailand: A Sustainable Tourism Perspective. Advanced Materials Research, vol. 616-618, pp. 1227-1230.

[5] American Institute of Architects, 2012, AIA Communities by Design's 10 Principles for Livable Communities,
http://www.aia.org/about/initiatives/AIAS075369, accessed 12 August 2012.

[6] Smart Growth Network, 2012, This is Smart Growth, http://www.smartgrowth.org/why.php, accessed 12 August 2012.

[7] Berke, P.R., Godschalk, D.R., Kaiser, E.J. and Rodriguez, D.A., 2006, Conceptual framework for land use planning, Urban land use planning (5th ed.), Chicago: University of Illinois, pp. 13-55.

[8] Lynch, K., 1960, The image of the city. Cambridge, Massachusetts: MIT Press.

[9] Tsaur, S.H. and Wang, C.H., 2007, The evaluation of sustainable tourism development by analytic hierarchy process and fuzzy set theory: an empirical study on the Green Island in Taiwan. Asia Pacific Journal of Tourism Research, vol.12, pp. 127-145.

[10] World Commission on Environment and Development, 1987, Report of the World Commission on Environment and Development: Our Common Future, http://www.un-documents.net/our-common-future.pdf, accessed 12 August 2012.

[11] United Nations Environment Programme, 2009, Sustainable coastal tourism: An integrated planning and management approach. France: Sustainable Consumption and Production Branch.

[12] World Tourism Organization, 2004, Concepts \& definitions: Sustainable development of tourism conceptual definition, http://www.world-tourism.org/frameset/frame_sustainable.ht ml, accessed 12 August 2012. 